\title{
Desensitizing ignition of energetic materials when exposed to accidental fire
}

Ronald J. Heaps, Michael A. Daniels, Kade Poper, Billy R. Clark, Michelle L. Pantoya

August 2015

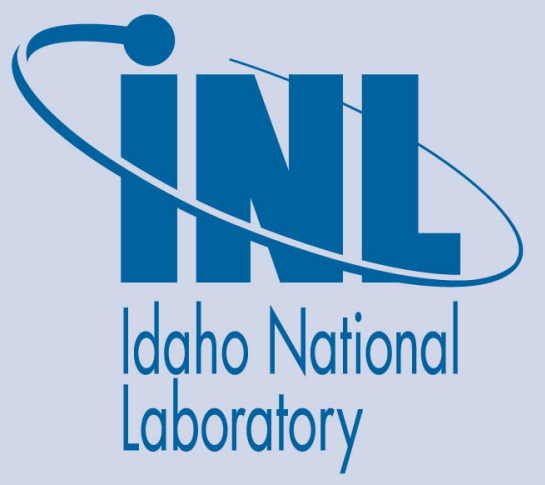

The INL is a U.S. Department of Energy National Laboratory operated by Battelle Energy Alliance 


\section{Desensitizing ignition of energetic materials when exposed to accidental fire}

Ronald J. Heaps, Michael A. Daniels, Kade Poper, Billy R. Clark, Michelle L. Pantoya

August 2015

Idaho National Laboratory Idaho Falls, Idaho 83415

http://www.inl.gov

Prepared for the U.S. Department of Energy Office of Nuclear Energy Under DOE Idaho Operations Office

Contract DE-AC07-05ID14517 
Mr. Kade Poper ${ }^{1}$, Mr. Billy R. Clark ${ }^{1}$, Dr. Michelle L. Pantoya ${ }^{1 *}$, Mr. Ronald Heaps, Mr. Michael A. Daniels ${ }^{2}$

${ }^{1}$ Texas Tech University, Department of Mechanical Engineering, Lubbock, TX 79409, USA

${ }^{2}$ Idaho National Laboratory, PO Box 1625, Idaho Falls, ID 83415

Corresponding Author Contact Information: Mechanical Engineering Department, Texas Tech University, $27037^{\text {th }}$ Street, Lubbock, TX 79409-1021; e-mail: michelle.pantoya@ttu.edu; phone: 806-834-3733

\begin{abstract}
Composite energetic materials combine fuel and oxidizers for high energy density exothermic reactions and are used for ordnance, industrial and localized power generation applications. This study focuses on examining an additive to a mixture of aluminum (Al) and copper oxide $(\mathrm{CuO})$ to decrease ignition sensitivity under accidental fire exposure conditions. Ammonium nitrate (AN) was incorporated into $\mathrm{Al}+\mathrm{CuO}$, as a 1:1 replacement for $\mathrm{CuO}$, for varied equivalence ratios and examined for ignition and combustion when exposed to slow and fast heating rate ignition conditions. The goal was to develop an $\mathrm{Al}+\mathrm{CuO}+\mathrm{AN}$ formulation that would perform comparable to $\mathrm{Al}+\mathrm{CuO}$ when intentionally ignited, but would not ignite in an accidental fire. Experimental results show that $\mathrm{Al}+\mathrm{CuO}+\mathrm{AN}$ with an equivalence ratio (ER) ranging from 4.05.5 inerts the reactants when exposed to slow heating conditions, yet ignites with comparative combustion performance to the baseline $\mathrm{Al}+\mathrm{CuO}$ mixture when exposed to fast heating conditions. These results are consistent with thermochemical simulations of the heat of combustion and adiabatic flame temperature for the respective reactions. This study presents a new approach for tailoring composite energetic materials toward accidental fire safety by exploiting the early stage decomposition kinetics of $\mathrm{AN}$, which are activated only by slow heating ignition conditions.
\end{abstract}


Key Words Thermites; Safety; Aluminum; Ammonium Nitrate; Ignition Sensitivity; Combustion; Energetic Materials

\subsection{Introduction}

Composite energetic materials (CEM) are mixtures of discretely separated fuel and oxidizer materials that combine to produce highly exothermic reactions. For example, the heat of combustion of aluminum (Al) fuel particles combined with copper oxide $(\mathrm{CuO})$ particles is 21 $\mathrm{kJ} / \mathrm{cm}^{3}$ [1], which is significantly greater than that of a monomolecular explosive such as trinitrotoluene (TNT), which has a heat of combustion of $8 \mathrm{~kJ} / \mathrm{cm}^{3}$ [2]. While CEM offer high energy density, their reaction is diffusion limited such that they fall short of matching the power produced by explosives [3]. Yet, CEM can be tailored toward an application. For example, high gas generating mixtures have potential for use in micro-thrusters [4], high flame temperature mixtures are ideal for welding and alloying metals [5], and many aluminum-based mixtures are used as primers in ordnance systems, replacing harmful lead-based formulations [6]. With widespread integration of these materials in industry, their potential for unintentional ignition becomes an increased safety concern.

Accidental explosions in pyrotechnic plants [7-9], for example, have prompted research on ways to desensitize composites to electrostatic discharge (ESD) ignition. Small concentrations of carbon black, and more recently, carbon nanotubes (CNT) have been shown to channel current through a composite without igniting the energetic [10 -12]. The CNT offer a conduit for ESD energy, bypassing the reactants in the composite. For micron scale powders, as little as 4 volume \% CNT will desensitize a mixture to ESD ignition [13].

In a similar vein, protection from unintended ignition in an accidental fire is also an important safety consideration. Accidental fires typically produce slower heating rate conditions 
than igniters. Hydrocarbon based fires can produce heating rates on the order of 100 degrees per minute [14]. In contrast, igniters in ordnance systems produce heating rates on the order of $10^{6}$ degrees per minute $[15,16]$.

This variation in heating rate enables the design and synthesis of CEM that only enable ignition when heated at a specific (high) heating rate. If the CEM is heated at lower heating rates, an additive to the CEM would decompose prior to the auto-ignition temperature and render the CEM inert. The ideal additive allows the mixture to respond to specific ignition stimuli with optimum combustion performance while preventing ignition when exposed to other stray or unintentional stimuli. This is a new direction for exploiting the tuneability of composite energetic materials and important for the full life-cycle safe handling of these materials.

To accomplish this goal, we started with a well characterized energetic composite for its increased safety to ESD stimuli [17]. The mixture is composed of micron scale aluminum (Al) particles combined with copper oxide $(\mathrm{CuO})$ particles and mixed to a specified stoichiometry. To this base mixture, carbon nanotubes (CNT) were added to obtain 4 vol \% concentration. This mixture has been shown to be desensitized to ESD ignition and also shown that the CNT additive has negligible effect on the mixtures overall combustion behavior [13]. For these reasons, starting with a base mixture insensitive to ESD ignition and tuning it toward insensitivity to fire exposure would advance the development of an overall safer formulation. The objective of this research was to introduce another additive that would make this formulation inert when subjected to slow heating processes (i.e., an accidental fire). To accomplish this neutralization, portions of the $\mathrm{CuO}$ were replaced with ammonium nitrate (AN) additive. Many additives were considered, but AN was selected based on its relatively low decomposition temperature (i.e., $\left.210^{\circ} \mathrm{C}[18]\right)$. The decomposition kinetics of AN have been well studied [19-21]. Generally, as 
long as chloride and some transition metal ions (e.g., chromium and copper) are not included in the reactants (because they can catalyze AN decomposition), then the heat liberated upon decomposition is $36 \mathrm{~kJ} / \mathrm{mole}[18,22]$. This is well below the apparent activation energy for many aluminum based energetics (i.e., $162 \mathrm{~kJ} / \mathrm{mol}$ ) [23]. In this way, AN could feasibly replace enough $\mathrm{CuO}$ such that under slow heating conditions $\mathrm{AN}$ decomposition would render the entire mixture too fuel rich to ignite. If AN decomposition can be activated for slow heating rate conditions, this mechanism could affect the accidental fire safety for a plethora of energetic composites.

\subsection{Material and Methods}

\subsection{Material Preparation}

The multi-walled carbon nanotubes (CNT) have an outer diameter of $20 \mathrm{~nm}$, an inner diameter of $3 \mathrm{~nm}$, and a length varying from 0.1-10 microns. Aluminum (Al) powder has an average spherical particle diameter of 4.0 microns and copper oxide $((\mathrm{CuO})$ powder has an average spherical particle diameter of $50 \mathrm{~nm}$. All powders were procured from Alpha Aesar (Ward Hill, MA). The AN was procured from Sigma Aldrich (St. Louis, MO) with average prill size of $1 \mathrm{~mm}$.

The mixture was designed to examine various stoichiometric proportions of $\mathrm{CuO}$ and $\mathrm{AN}$

oxidizer combination with $\mathrm{Al}$ as shown in the following reaction, Eq. (1). For every mole of $\mathrm{CuO}$ removed, 1.00 mole of $\mathrm{AN}$ is added (i.e., a 1:1 ratio of $\mathrm{CuO}: \mathrm{AN}$ was used). It is also noted 
that 4 vol\% CNT is added to all mixtures but not assumed as an active participant in the reaction. The CNT additive was included to desensitize the mixture to ESD ignition.

$$
3 \mathrm{CuO}+3 \mathrm{NH}_{4} \mathrm{NO}_{3}+4 \mathrm{Al} \rightarrow 2 \mathrm{Al}_{2} \mathrm{O}_{3}+3 \mathrm{Cu}+3 \mathrm{~N}_{2}+6 \mathrm{H}_{2} \mathrm{O} \quad \text { Eq. (1) }
$$

Stoichiometry is defined in terms of equivalence ratio (ER) and is the ratio of fuel/oxidizer mass ratio in the actual mixture to the fuel/oxidizer mass ratio in a stoichiometric mixture (see Eq. (1)). In this way, mixtures with ER $>1.0$ are fuel rich (e.g. for stoichiometric $\mathrm{ER}=1.0)$

Once proportioned, the reactants were suspended in hexanes and sonicated in a Misonix S3000 sonicator for a total of one minute in ten second intervals. Sonication has been shown to be effective for producing homogeneous composites [10]. Post sonication, the mixtures were poured into a Pyrex ${ }^{\circledR}$ dish and the hexane evaporated while in a fume hood. The mixed powder was then reclaimed for further experimentation.

Mixtures were prepared for ER ranging from 1.0 - 5.5. For each ER, two mixtures were prepared: (1) $\mathrm{Al}+\mathrm{CuO}+\mathrm{CNT}$ (i.e., baseline mixture); and (2) $\mathrm{Al}+\mathrm{CuO}+\mathrm{CNT}+\mathrm{AN}$ (i.e., $\mathrm{AN}$ additive mixture) such that the $\mathrm{AN}$ additive replacing a portion of $\mathrm{CuO}$ could be compared to the baseline mixture without AN.

\subsection{Experimental Methods}

Three stages of experimentation included: evaluating combustion pre-heat treatment, exposing samples to heat treatment simulating accidental fire, and evaluating combustion postheat treatment. In all stages experiments were performed in triplicate to establish repeatability.

In the first stage, a $50 \mathrm{mg}$ powder sample for each ER was ignited with a hot wire and the

combustion was recorded using a high speed camera (see Fig. 1 for schematic of setup). A Nichrome wire is a common hot wire ignition source and provides in excess of $10^{6}$ degrees per 5 | P a g e 
minute heating rate stimulus [24]. A variable voltage source was used to apply 15 volts to the Nichrome wire in order to achieve the temperature required for ignition. A Phantom v7 (Vision Research) high speed camera was used to record the combustion event using an F-Stop of 25 and captured images at 10,000 frames per second.

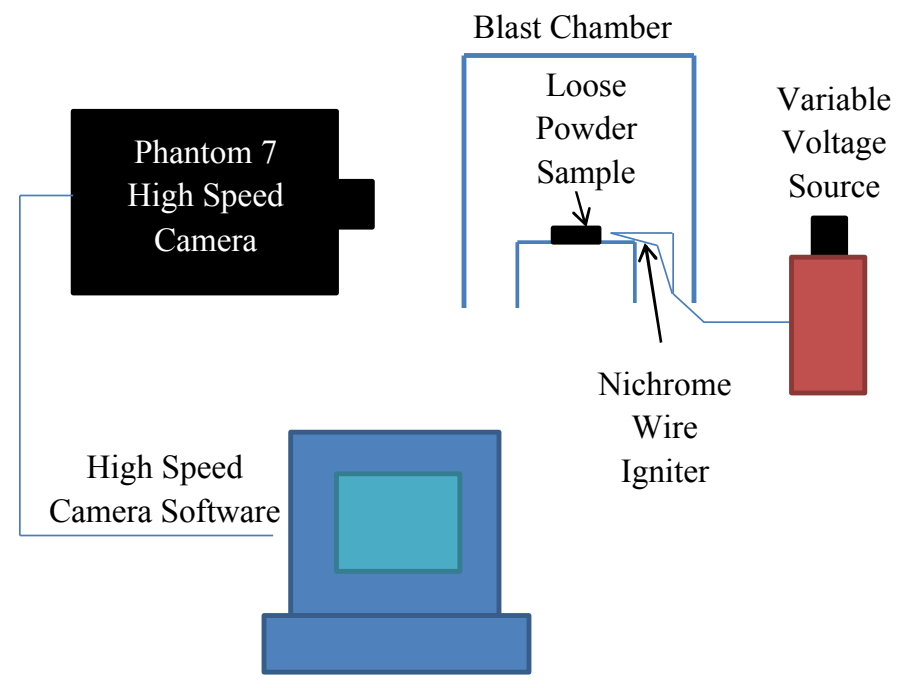

Figure 1. Experimental setup including high speed camera, blast chamber housing sample and Nichrome wire ignition system.

The second stage of experimentation exposed each $50 \mathrm{mg}$ sample to simulated accidental fire conditions using a vacuum oven (NeyTech Qex) in an air environment. The samples were heated at 10 degrees per minute from room temperature to $230^{\circ} \mathrm{C}$ and held at this temperature for 1 hour, then cooled to room temperature. An InstruNet (model 100) data acquisition board and InstruNet software were used to record temperature. This pre-heat temperature is purposefully above the decomposition temperature of AN so that the effects of $\mathrm{AN}$ decomposition on combustion could be evaluated. While varying the heating rate to simulate a variety of fire 
exposure conditions was considered, these initial tests were performed for one heating rate to establish the feasibility of this approach.

In the third stage, post-heat treatment, $50 \mathrm{mg}$ samples were ignited using Nichrome wire and combustion recorded with the high speed camera at the same operating conditions prior to heat treatment and shown in Fig. 1. Post-heat treatment, the optimum sample stoichiometries did not ignite to the point that they could maintain self-sustained energy propagation.

As a further evaluation of these optimum stoichiometries, pre- and post-heat treated samples were examined for their ability to ignite another energetic mixture using a flame tube apparatus. In this setup, the tube is $10 \mathrm{~cm}$ long with $5 \mathrm{~mm}$ inside diameter (see Fig. 2). This apparatus is commonly used to quantify one-dimensional energy propagation in terms of flame speed for powder CEM $[24,25]$. For this test, half of the tube was filled with $125 \mathrm{mg}$ of pre- or post-heat treated sample and the other half was filled with $125 \mathrm{mg}$ of an ignition sensitive mixture of nano-scale particles of aluminum and molybdenum trioxide $\left(\mathrm{Al}+\mathrm{MoO}_{3}\right)$ [26]. This is one of the most ignition sensitive mixtures and a conservative evaluation of the pre- and postheat treated sample ability to initiate a secondary reaction.

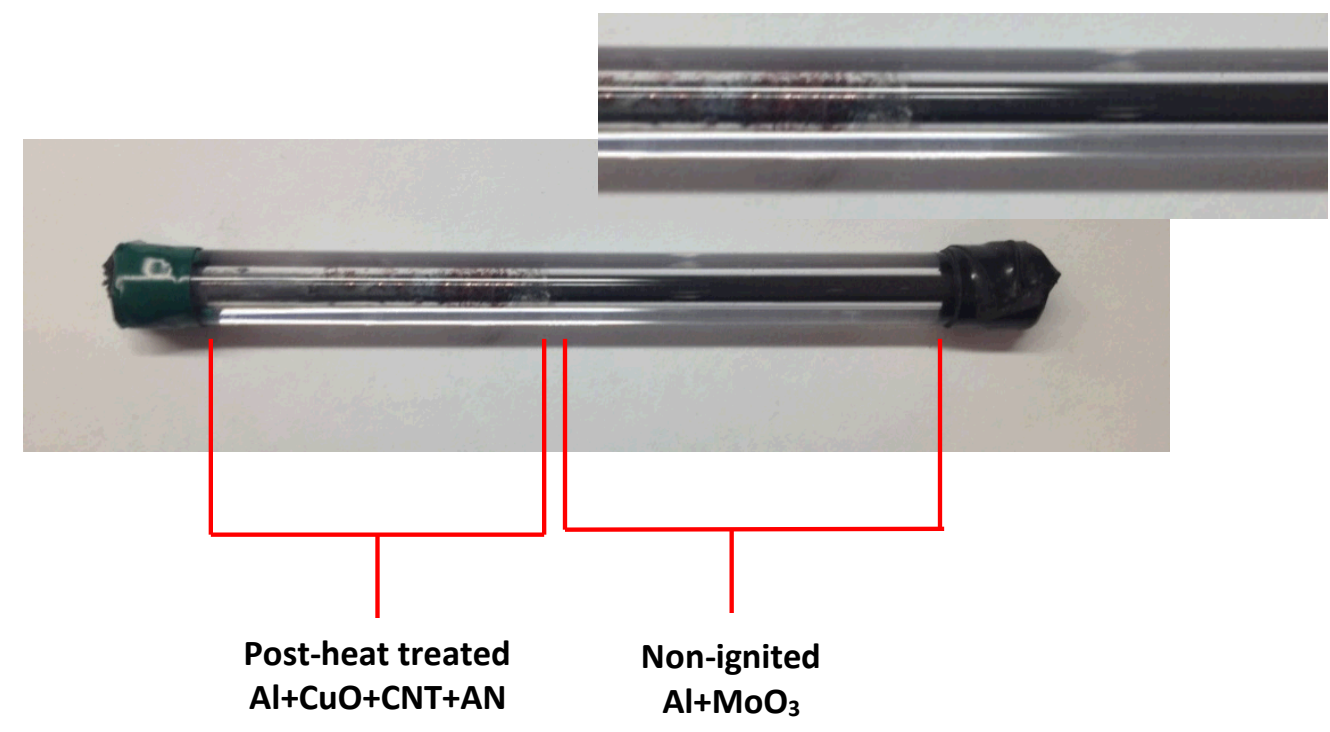


Figure 2. Flame tube apparatus shown AFTER an experiment in which the postheat treated primer formulation with an $\mathrm{ER}=\mathbf{4 . 0}$ was ignited but did not ignite the highly ignition sensitive $\mathrm{Al}+\mathrm{MoO}_{3}$ powder thermite. An enlarged view of the tube at the junction of the two powders is shown as an inset.

\subsection{Results and Discussion}

Table 1 summarizes the results. The most interesting finding is that an ER $=4.0$ is a threshold for activation of the decomposition mechanism that was designed to inert the entire mixture post-heat treatment. This is the ER for which unsustained propagation and a non-ignition was repeatedly observed.

Table 1. Results of response to $\mathrm{Al}+\mathrm{CuO}+\mathrm{CNT}+\mathrm{AN}$ formulations pre- and post-heat treatment as a function of equivalence ratio (ER). Notes provide more perspective on observations.

\begin{tabular}{|c|c|c|c|}
\hline ER & $\begin{array}{l}\text { Pre-Heat } \\
\text { Treatment } \\
\text { Ignition }\end{array}$ & $\begin{array}{l}\text { Post-Heat } \\
\text { Treatment } \\
\text { Ignition }\end{array}$ & Notes \\
\hline 1.6 & YES & N/A & Ignited during bake \\
\hline 1.7 & YES & YES & \\
\hline 1.8 & YES & YES & \\
\hline 2.2 & YES & YES & \\
\hline 2.3 & YES & YES & \\
\hline 2.3(AN Only) & YES & $\mathrm{NO}$ & $\begin{array}{ll}\text { Complete } & \text { AN decomposition } \\
\text { preventing } & \text { post-heat treatment } \\
\text { ignition } & \end{array}$ \\
\hline 3.0 & YES & YES & \\
\hline 3.5 & YES & $\mathrm{NO} / \mathrm{YES}$ & Non-repeatable results \\
\hline 4.0 & YES & NO & $\begin{array}{l}\text { Small amount of propagation but not } \\
\text { self-sustained }\end{array}$ \\
\hline 4.5 & YES & NO & Almost no propagation \\
\hline 5.0 & YES & $\mathrm{NO}$ & $\begin{array}{l}\text { No propagation but entire } 50 \mathrm{mg} \\
\text { sample was red hot and turned to ash }\end{array}$ \\
\hline 5.5 & YES & NO & $\begin{array}{l}\text { Similar to } 5.0 \text { but powder pile } \\
\text { exhibited slower heating }\end{array}$ \\
\hline
\end{tabular}




\begin{tabular}{|c|c|c|c|}
\hline 6.0 & YES & $\mathrm{NO}$ & $\begin{array}{l}\text { Similar to } 5.5 \text { but even slower. No } \\
\text { visible flame. }\end{array}$ \\
\hline
\end{tabular}

All of the samples that included AN demonstrated comparable visual combustion to the baseline $\mathrm{Al}+\mathrm{CuO}+\mathrm{CNT}$ at the corresponding equivalence ratio pre-heat treatment. $\mathrm{AN}$ effectively replaced $\mathrm{CuO}$ in 1:1 molar ratios and maintained comparable combustion behavior. Figure 3 shows still frame images of $E R=4.0$ threshold case. Notice that the baseline mixture (see Fig. 3A) and the AN additive mixture (Fig. 3B) demonstrate similar reactivity prior to heat treatment. However, post-heat treatment (Fig. 3C), the mixture does not achieve a self-sustained reaction. 


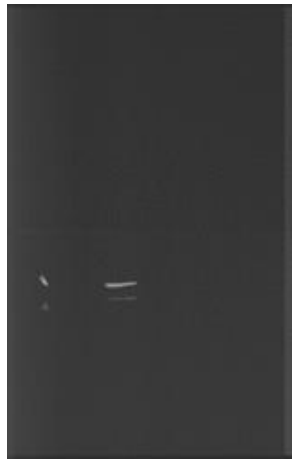

Time $=0$ sec

A

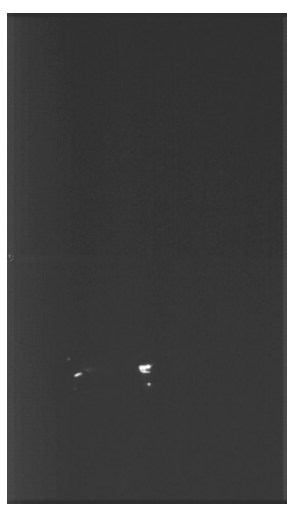

Time $=0$ sec

B

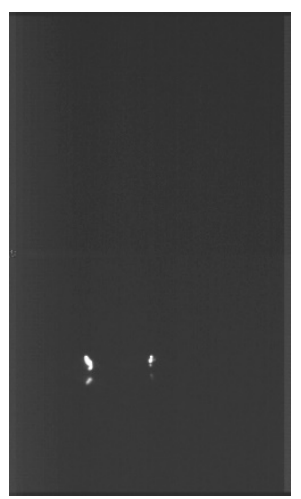

Time $=0$ sec

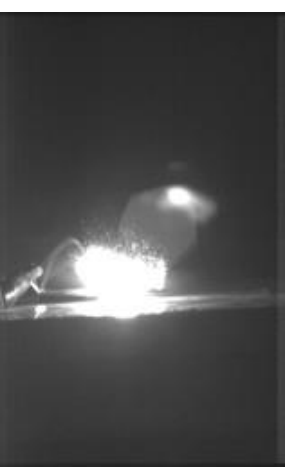

Time $=0.0001 \mathrm{sec}$

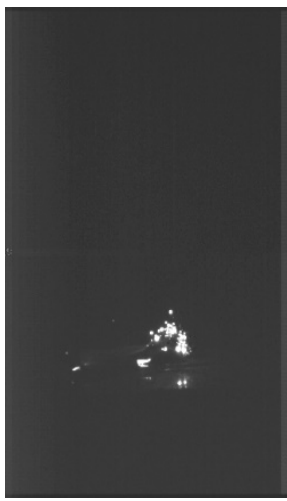

Time $=0.0003 \mathrm{sec}$

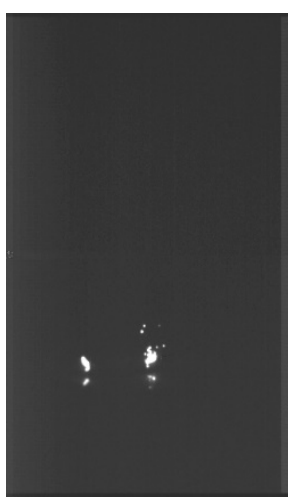

Time $=0.0004 \mathrm{sec}$

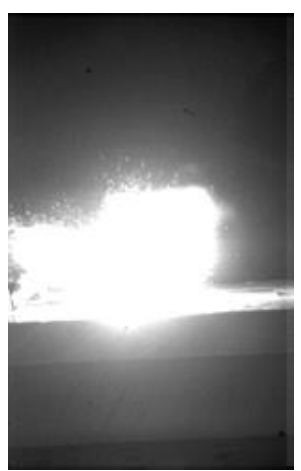

Time $=0.0002 \mathrm{sec}$

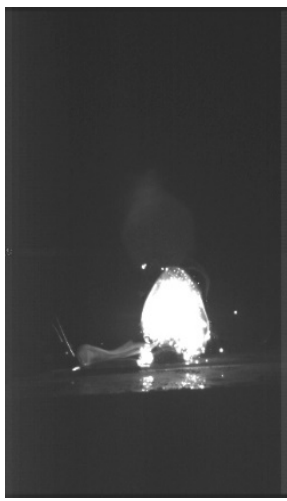

Time $=0.0006 \mathrm{sec}$

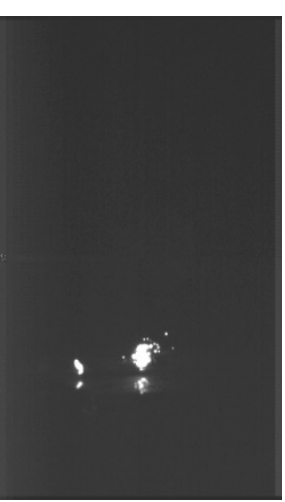

Time $=0.0008 \mathrm{sec}$

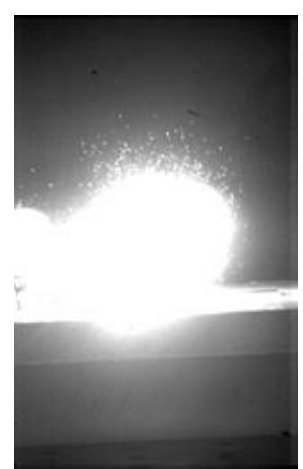

Time $=0.0003 \mathrm{sec}$

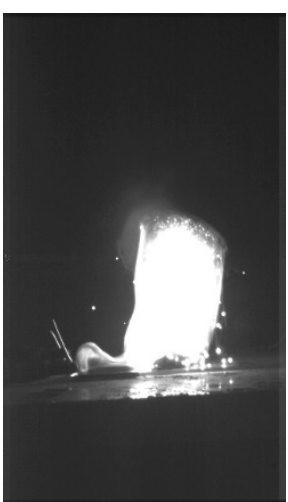

Time $=0.001 \mathrm{sec}$

C

Figure 3. Representative still frame images of $\mathrm{A} . \mathrm{Al}+\mathrm{CuO}+\mathrm{CNT}$ reaction; $\mathrm{B}$. $\mathrm{Al}+\mathrm{CuO}+\mathrm{CNT}+\mathrm{AN}$ reaction pre-heat treatment; and, $\mathrm{C}$. $\mathrm{Al}+\mathrm{CuO}+\mathrm{CNT}+\mathrm{AN}$ reaction postheat treatment, all at $E R=4.0$ 
Thermal chemical calculations for the above reactions were performed using REAL code simulation software (Timtec L.L.C.) for constant specific volume of $0.001 \mathrm{~m}^{3} / \mathrm{kg}$ and an internal energy equal to zero. Both adiabatic flame temperature (Fig. 4A) and heat of combustion (Fig. 4B) as a function of equivalence ratio ranging from 1.0-5.5 were simulated. In the post-heat treated simulations the assumption is that $\mathrm{AN}$ does not participate in the reaction such that the products $\mathrm{H}_{2} \mathrm{O}$ and $\mathrm{N}_{2}$ do not exist. The simulations indicate that post-heat treatment decomposition of AN renders the reaction excessively fuel rich such that flame temperatures drop below the limit for a self-sustaining propagation, identified as $2000 \mathrm{~K}[27,28]$. In fact, for 4.0 ER, the flame temperature drops just below the $2000 \mathrm{~K}$ limit corresponding well with our experimental observations of limited reactivity for that formulation (see Fig. 3C). AT ER $=3.5$ results are unrepeatable (Table 1), possibly because the $2000 \mathrm{~K}$ threshold for energy propagation is just barely achieved theoretically. Pre-heat treatment flame temperatures and heats of combustion are comparable for all formulations examined, such that these simulations are also an indication that $\mathrm{AN}$ does not significantly reduce the reactivity of the baseline mixture. 

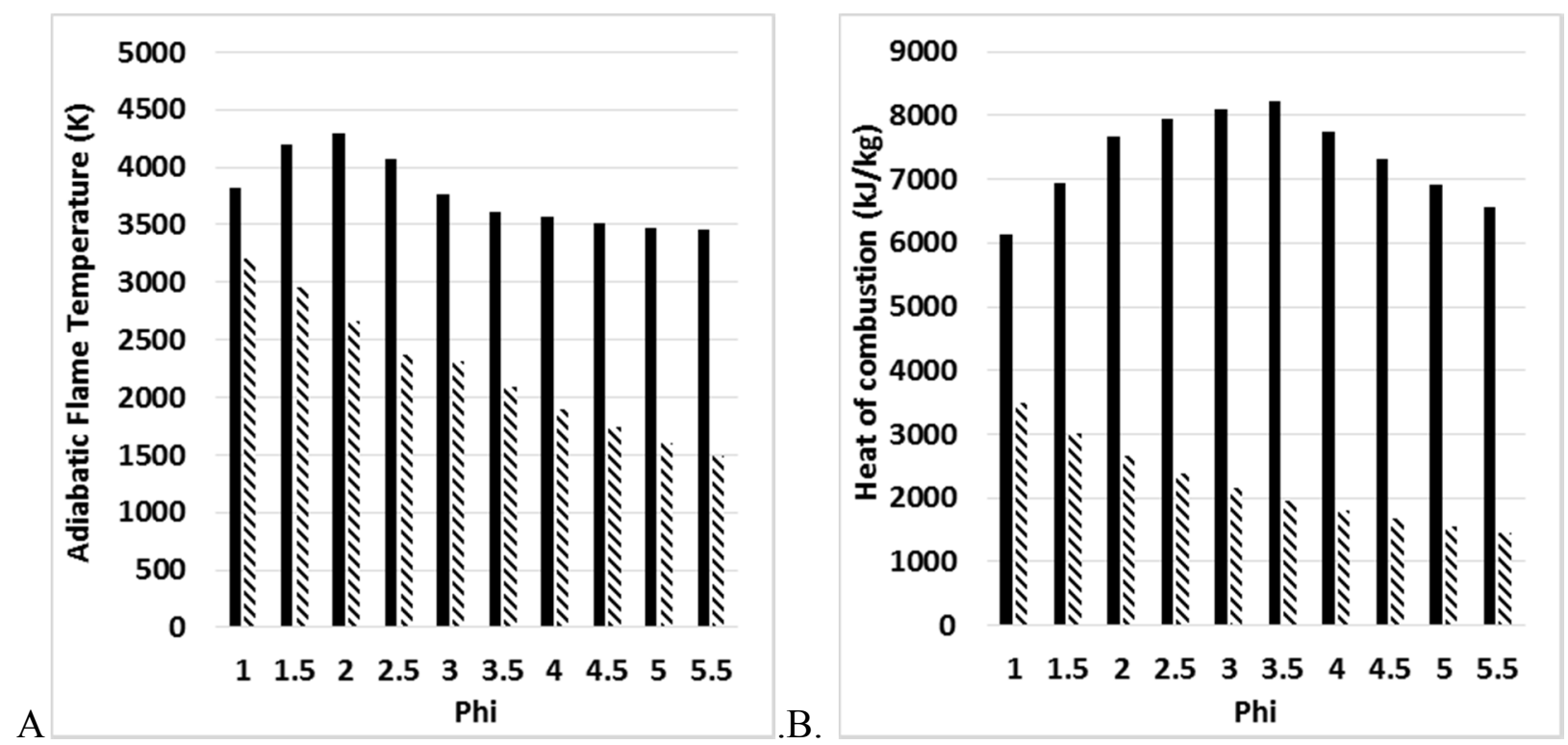

Figure 4. REAL code simulations for the reaction in Eq. (1) with varying stoichiometry from 1.0 to 5.5 equivalence ratio (i.e., Phi). Solid bars represent pre-heat treatment and hatched bars represent post-heat treatment. Post-heat treatment simulations (i.e., hatched bars) assume no $A N$ in reactants and no $\mathrm{H}_{2} \mathrm{O}$ or $\mathrm{N}_{2}$ in products. A. adiabatic flame temperature; and, $B$. heat of combustion.

Optimum stoichiometries (i.e., $\mathrm{ER}=4.0$ and 4.5 ) that passed the pre-heat treatment test and showed non-ignition post-heat treatment, were further tested as primer candidates using the flame tube apparatus described in Fig. 2. Pre-heat treatment $\mathrm{Al}+\mathrm{CuO}+\mathrm{CNT}+\mathrm{AN}$ successfully ignited the $\mathrm{Al}+\mathrm{MoO}_{3}$ mixture. Post-heat treatment, the $\mathrm{Al}+\mathrm{MoO}_{3}$ could not ignite. This assessment was performed for multiple tests to establish repeatability.

\subsection{Conclusions}

This study presents a new way to tailor energetic material reactants toward their safer functionality. Aluminum $(\mathrm{Al})$ and copper oxide $(\mathrm{CuO})$ powders combined with 4 vol \% carbon nanotubes $(\mathrm{CNT})$ was the baseline mixture considered. Ammonium nitrate $(\mathrm{AN})$ as an additive to $\mathrm{Al}+\mathrm{CuO}+\mathrm{CNT}$ was examined by replacing a portion of $\mathrm{CuO}$ with equal mole fractions of $\mathrm{AN}$ up 
to $50 \%$. This study explored low temperature $\mathrm{AN}$ decomposition as a mechanism to inactivate the $\mathrm{Al}+\mathrm{CuO}+\mathrm{CNT}+\mathrm{AN}$ reaction when exposed to heating conditions simulating accidental fire. This was a proof of concept study that established a 4.0 equivalence ratio threshold when $50 \%$ of $\mathrm{CuO}$ is replaced with $\mathrm{AN}$ to cause a non-ignition after heat treatment exposure. The simulated fire conditions were achieved using a vacuum oven operating in an air environment with programmed heating at 100 degrees per minute to $230^{\circ} \mathrm{C}$. Thermal chemical software was also used to predict the adiabatic flame temperature and heat of combustion pre- and post- heat treatment. Results from the simulations are in excellent agreement with the experimental observations that show unsustained propagation for reactions that produce an adiabatic flame temperature below $2000 \mathrm{~K}$, an established limit for self-sustained energy propagation for energetic composites. This mechanism may be extended to higher heating rates as long as the conditions allow enough time for $\mathrm{AN}$ to fully decompose before the composite reaches its ignition temperature. This study is the first to explore a means to increase the fire safety of a composite energetic material in any field application.

\section{Acknowledgements}

The authors M. Pantoya, B. Clark and K. Poper are grateful for support from the Army Research Office contract number W911NF-11-1-0439 and encouragement from our program manager, Dr. Ralph Anthenien. Idaho National Laboratory is also gratefully acknowledged for supporting this collaborative work with internal funds via the LDRD program. Matt Simmons at Texas Tech University is gratefully acknowledged for the graphical abstract cover art. 


\section{References}

[1] Fischer SH, Grubelich MC. Theoretical energy release of thermites, intermetallics, and combustible metals, Sandia National Laboratory Report No.: SAND--98-1176C; CONF980728--; Other: ON: DE98005512; BR: 400403310; TRN: US200223\%\%671, 1998.

[2] Urbanski, T., Chemistry and Technology of Explosives, Pergamon Press, New York, NY, 389-391, 1964.

[3] Teipel, U., Energetic Materials: Processing and Characterization of Particles, Wiley - VCH Publisher, 2000.

[4] Staley, C. S., Raymond, K. E., Thiruvengadathan, R., Apperson, S. J., Gangopadhyay, K., Swaszek, S. M., Taylor, R. J., Gangopadhyay, S., Fast-impulse nanothermite solidpropellant miniaturized thrusters, Journal of Propulsion and Power 29(6), 1400-1409, 2013.

[5] Francisco, A., Delgado, A., Frias, J., Rubio, M., White, C., Narayana, S., Ashvin, K., Shafirovich, E., Combustion of Thermites in Reduced Gravity for Space Applications, Journal of Thermophysics and Heat Transfer 27(3), 576-583, 2013.

[6] Giles, J., Collateral Damage, Nature 427, 579-581, 2014.

[7] Basco, A., Camarota, F. Salzano, E., The Risk of Storage Plant of Pyrotechnics, Chemical Engineering Transactions 19, 231-236, 2010.

[8] Lefin, Y., Mavrothalassitis, G., Pineau, J.P., Knowledge Gained from Hazard Studies and Acciendents Investigations, European Meeting on Chemical Industry and Environment, Girone, Spain, 1993.

[9] Associated Press, 2 Bodies Found After UK Fireworks Warehouse Blaze, Stafford, England, October 31, 2014,

[10] Collins, E., Skelton, B., Pantoya, M., Irin, F., Green, M., Daniels, M., Ignition Sensitivity and Electrical Conductivity of a Composite Energetic Material with Conductive Nanofillers, In Review Combustion and Flame, December 2014.

[11] Collins, E., Gesner, J.P., Pantoya, M.L., Daniels, M.A., Synthesizing Aluminum Particles Towards Controlling Electrostatic Discharge Ignition Sensitivity, Journal of Electrostatics 72(1), 28-32, 2014.

[12] Collins, E., Pantoya, M.L., Neuber, A., Daniels, M., Prentice, D., Piezoelectric Ignition of Nanocomposite Energetic Materials, Journal of Propulsion and Power 30(1), 15-18, 2014. 
[13] Poper, K., H., Collins, E.S., Pantoya, M.L., Daniels, M.A., Controlling the Electrostatic Discharge Ignition Sensitivity of Composite Energetic Materials Using Carbon Nanotube Additives, Journal of Electrostatics 72, 428-432, 2014.

[14] Babrauska and Peacock, Heat Release Rate: The Single Most Important Variable in Fire Hazard,Fire Safety Journal 18, 255-272, 1992

[15] Goetz, R., Hesse, P.W., Lenko, D., Electronic Primer Ignition System, US Patent 5,485,786, Jan. 23, 1996.

[16] Beltz, D.R., Multi-Strand Ignition Systems, US Pantent 4,917,017, April 17, 1990.

[17] Weir, C. Pantoya, M.L., G. Ramachandran, T. Dallas, D. J. Prentice, M. A. Daniels, Electrostatic Discharge Sensitivity and Electrical Conductivity of Composite Energetic Materials, Journal of Electrostatics 71(1), 77-83, 2013.

[18] Pradyot P., Handbook of Inorganic Chemicals, McGraw-Hill, 2002.

[19] Brill, T.B., Brush, P.J., Patil, D.G., Thermal Decomposition of Energetic Materials 58. Chemistry of Ammonium Nitrate and Ammonium Dinitramide Near the Burning Surface, Combustion and Flame 92 (1-2), 178-186, 1993.

[20] Oxley, J.C., Kaushik, S.M., Gilson, N.S., Thermal Decomposition of Ammonium NitrateBased Composites, Thermochimica Acta 153, 269-286, 1989.

[21] Rosser, W.A., Inami, S.H., Wise, H., The Kinetics of Decomposition of Liquid Ammonium Nitrate, Journal of Physical Chemistry 67(9), 1753-1757, 1963.

[22] Keenan, A.G., Notz, K., Franco, N.B., Synergistic Catalysis of Ammonium Nitrate Decomposition, Journal of the American Chemical Society 91(12), 3168-3171, 1969.

[23] Hunt, E.M., Pantoya, M.L., Ignition Dynamics and Activation Energies of Metallic Thermites: From Nano- to Micron-Scale Particulate Composites, Journal of Applied Physics 98(3), 034909, 2005.

[24] Levitas, V.I., Asay, B.W., Son S.F., and Pantoya, M.L., "Mechanochemical Mechanism for Fast Reaction of Metastable Intermolecular Composites Based on Dispersion of Liquid Metal," Journal of Applied Physics 101(8), 083524, 2007.

[25] Bockmon, B.S., Pantoya, M.L., Son, S.F., Asay, B.W., Mang, J.T., Combustion Velocities and Propagation Mechanisms of Meta-stable Intermolecular Composites, Journal of Applied Physics 98(6), 064903, 2005. 
[26] Shaw, B.D., Pantoya, M.L., Dikici, B., Detonation models of fast combustion waves in nanoscale $\mathrm{Al}-\mathrm{MoO}_{3}$ bulk powder media, Combustion Theory and Modelling 2012. DOI:10.1080/13647830.2012.721898

[27] Wang, L.L., Munir, Z.A., Maximov, Y.M., Review: Thermite reactions: their utilization in the synthesis and processing of materials, Journal of Materials Sciences 28, 3693-3708, 1993.

[28] Moore, J.J., Combustion Synthesis of Advanced Materials: Part I Reaction Parameters, Progress in Materials Science 39 (4-5), 243-273, 1995. 